www.jmscr.igmpublication.org

Impact Factor (SJIF): 6.379

Index Copernicus Value: 71.58

ISSN (e)-2347-176x ISSN (p) 2455-0450

crossref DOI: _https://dx.doi.org/10.18535/jmscr/v6i2.136

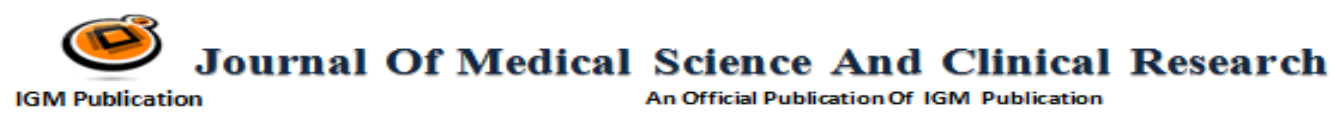

\title{
Prevalence and causes of Anaemia in Children: A Hospital-Based Diagnostic Study
}

\author{
Authors \\ Rastogi Parag ${ }^{1}$, Sharma Sushil Kumar ${ }^{2 *}$ \\ ${ }^{1}$ Assist. Prof, Department of Physiology, VIMS Gajrola (UP) \\ ${ }^{2 *}$ Assist. Prof, Department of Physiology, VIMS Gajrola (UP) \\ *Corresponding Author \\ Dr Sushil Kumar Sharma \\ Assist. Prof, Department of Physiology, VIMS Gajrola (UP) India \\ Email:dr.sushilsharma1989@gmail.com
}

\begin{abstract}
Anaemia in children is a major public health problem throughout the world. It is estimated that at least onethird of the population has been at one-time anemic. It is often multifactorial, iron deficiency being the most frequent etiology and reasons like malaria endemicity, poor nutrition including micronutrient deficiency, haemoglobinopathies, frequent bacterial infections and high parasitic infestations have been given for these high prevalence rates. The ranges for $\mathrm{Hb}$ were first derived from 554 subjects in whom laboratory values for serum iron/iron-binding capacity, mean corpuscular volume, and erythrocyte protoporphyrin were all normal $(\geq 16 \%, \geq 80 \mathrm{fl}$, and $\leq 75 \mu \mathrm{g} / \mathrm{dl}$ red blood cells, respectively). Using these reference standards, the prevalence of Anaemia ( $\mathrm{Hb}$ values below the $95 \%$ reference range for age and sex) among the 354 subjects with complete laboratory results was highest in infants (5.8\%), teenage girls (5.10\%), young women (5.9\%), and elderly men (4.5\%). Chronic Anaemia may impair growth, cardiac function and cognitive development in infants but other consequences are rather poorly explored more thoroughly. Chronic disorders and iron deficiency were the most common causes of Anaemia. Anaemia was frequently diagnosed in this series of elderly patients. Partly treatable nutritional deficiencies, such as iron or folate deficiency, were identified as possible causes. A complex and heterogeneous interplay of chronic inflammation, functional iron deficiency, and renal impairment was identified in a large proportion of patients. Measures directed at prevention and control of anemia, include increased coverage of supplementation and fortification programs are strongly recommended.
\end{abstract}

Keywords: Anaemia, iron-deficiency hemoglobin, prevalence of Anaemia, hemoglobin.

\section{Introduction}

National Health and Nutrition Examination Survey (NHANES II) provide adequate data on which to base estimates of the prevalence of irondeficiency Anaemia and the Anaemia of inflammatory disease (Mozaffarian et al. 2015).
An edited data tape for the laboratory analyses that are relevant to iron deficiency (Bothwell et al., 1979; Dallman et al., 1980). Values for serum ferritin on a subpopulation of 157 subjects were used in certain of the analyses. The prevalence of Anaemia is usually defined in terms of the 
percentage of individuals with $\mathrm{Hb}$ values below a 95\% reference range (Osei-Bimpong et al., 2012; Hong et al., 2012). 95\% reference ranges for $\mathrm{Hb}$ concentration was taken from NHANES II because this large and carefully conducted survey offered the prospects of providing a stronger basis for reference values than previously available. For this purpose, we included only those subjects who provided venous blood samples and excluded all subjects with pregnancy, hemoglobinopathies, or an abnormality in iron/total iron-binding capacity (Fe/TIBC), mean corpuscular $\mathrm{Hb}$ (MCV), or erythrocyte protoporphyrin (EP). These reference ranges were then used as a basis for estimates of the prevalence of Anaemia, ie, the percentage of individuals with $\mathrm{Hb}$ values below the $95 \%$ reference range for age and sex.

Anaemia can also be considered in terms of the depression of $\mathrm{Hb}$ concentration by the presence of common abnormalities such as iron deficiency or inflammatory disease (in which laboratory abnormalities are similar), even if that depression occurs within the "normal" reference range. The relative prevalence of Anaemia defined in this manner was estimated from the degree to which the frequency distribution for $\mathrm{Hb}$ concentration shifted toward higher values after exclusion of subjects who had one or more laboratory values indicative of iron deficiency and/or inflammatory disease. Anaemia is a common problem in elderly patients that usually develops gradually, allowing the body to adapt. Its effects can be life threatening, particularly as part of various comorbidities in geriatric patients, and it is therefore a difficult diagnostic and therapeutic dilemma for medical practitioners (Merono et al., 2012; Pasricha et al., 2010). Anaemia is an important sign of disease and an evaluation is almost always warranted to determine the underlying cause. It has been shown that Anaemia defined according to the WHO criteria (hemoglobin level $\leq 13 \mathrm{~g} / \mathrm{dl}$ in men and $\leq 12 \mathrm{~g} / \mathrm{dl}$ in women) is associated with increased mortality in elderly community residents (Moura, 2015). Imbalanced production and removal ratio results in Anaemia, which may be acute and rapidly life threatening or chronic. Children are especially at risk of Anaemia: iron deficiency is the most frequent cause at this age because of the disequilibrium between rapid growth and insufficient iron intakes (Wang et al., 2013; Laxmaiah et al., 2007).

\section{Signs and symptoms of Anaemia}

When Anaemia is present insidiously, such as with iron deficiency, the diagnosis is often delayed. Cutaneous pallor is not helpful because of the wide variability in skin pigmentation depending on ethnic origin. Conversely, conjunctival pallor, tongue pallor, and pallor of palms and soles seem to be more reliable (Chalco et al., 2005; Kalantri et al., 2010). Reduced food intake and fatigue may be frequent (Teunissen et al., 2014; Panepinto et al., 2014). The degree of tachycardia is correlated with the $\mathrm{Hb}$ level and reflects the tolerance of Anaemia ( $\mathrm{Gv}$ et al., 2014). Signs of hemolysis may be present, such as jaundice or dark urine. Dysmorphic features may help to diagnose a thalassemic syndrome (frontal bossing, prominent malar eminence, and depressed bridge of the nose).

Vitamin B12 deficiency Anaemia was diagnosed if the serum vitamin B12 level was low (less than $211 \mathrm{ng} / \mathrm{l}$ ), associated with macrocytosis (mean corpuscular hemoglobin $>98$ fl). Folate deficiency Anaemia was diagnosed if the erythrocyte folate level was low (less than 186 $\mu \mathrm{g} / \mathrm{l})$ combined with macrocytosis. The diagnosis of hematological malignant conditions was based on examinations of the bone marrow aspirate and biopsy. Renal disease was accepted as the cause of Anaemia if the patient was known to have chronic renal failure, or had small kidneys on ultrasound examination and the results of the iron studies, serum vitamin B12 levels and erythrocyte folate levels were normal (Wonke et al., 1998). Dietary iron intake Overall, women do not make major changes in their dietary habits during pregnancy (Trygg et al., 1995; Pedersen et al., 2003), which means that the results of nutrition surveys in nonpregnant women can be transferred to pregnant and postpartum women. Danish women of 
reproductive age have a mean dietary iron intake of $\sim 9 \mathrm{mg} /$ day (Pedersen et al., 2003), which means that more than $90 \%$ of the women have an intake below the recommended daily allowance of $\sim 18 \mathrm{mg} /$ day (NCM, 2004). $96 \%$ of the women had a dietary iron intake below the recommended 18 mg/day (Trygg et al. 1995; NCM, 2004). In the third trimester, there is too short time for oral iron treatment to be effective in the correction of Anaemia due to the limited iron absorption capacity. Gastrointestinal iron absorption is regulated according to body iron reserves and the intensity of erythropoiesis. Exhausted body iron reserves in otherwise healthy women will increase the intestinal iron absorption (Krafft and Breymann 2011). In women who do not respond to oral iron, i.v. iron therapy should be considered. The recently introduced third-generation i.v. iron compounds are ferric iron carboxymaltose (Ferinject; Vifor Pharma Ltd.) (Ferinject, 2011; Lyseng-Williamson and Keating, 2009) and ferric iron isomaltoside 1000 (Monofer Pharmacosmos Ltd. 2011).

\section{Material and Methods}

The study was conducted in VIMS and their associated hospital Gajrola (Uttar Pradesh) India from 2014 to 2016. The sample design certain subgroups in the population that were of special interest for nutritional assessment were oversampled: preschool children (6 months through $5 \mathrm{yr}$ old), persons 62 through $75 \mathrm{yr}$ old, and the poor (persons living in local areas). For the purposes of this report, we excluded 57 subjects from the latter group because of pregnancy $(\mathrm{n}=20)$, abnormal $\mathrm{Hb}$ electrophoresis ( $\mathrm{n}=35$ : primarily $\mathrm{Hb} \mathrm{AS}, 15 ; \mathrm{AC}, 10$; elevated F, 5; and elevated A2, 5), or because only skin puncture blood could be obtained $(n=2)$. These exclusions involved primarily young women (pregnancy), hemoglobinopathies, and children under the age of $5 \mathrm{yr}$ (skin puncture blood). The remaining group of subjects was the basis for (Table. 1 and Table. 2.) was based on those of the subjects who had normal values for Fe/TIBC,
$\mathrm{MCV}$, and EP by criteria that will be described below. Although (Table. 1 and Table. 2.) show actual numbers of subjects, the laboratory findings for each person in the sample were inflated by the reciprocal of selection probabilities, adjusted to account for persons who were not examined, and stratified afterward according to race, sex, and age, so that the final.

\section{Laboratory Analysis and Definition of Anaemia}

Anaemia was defined according to World Health Organization criteria as Hemoglobin $(\mathrm{Hb})<120$ $\mathrm{g} / \mathrm{l}$ in women and $<130 \mathrm{~g} / \mathrm{l}$ in men (WHO, UNICEF, UNU 2001; FAO, WHO, 1992). Its severity was graded as mild when $\mathrm{Hb}$ was 100 $129 \mathrm{~g} / \mathrm{l}$ in men and 100-119 $\mathrm{g} / \mathrm{l}$ in women, and either moderate or severe when $\mathrm{Hb}$ was 70-99 g/l and less than $70 \mathrm{~g} / \mathrm{l}$, respectively in women. In men, it was graded either moderate or severe when $\mathrm{Hb}$ was 80-109 $\mathrm{g} / \mathrm{l}$ and less than $80 \mathrm{~g} / \mathrm{l}$, respectively (WHO, UNICEF, UNU 2001; FAO, WHO, 1992). Anaemic status, severity and its possible causes were identified from admission blood samples with hematinic parameters like serum ferritin, vitamin B12 and folate levels in most of the patients. In patients with normal hematinic parameters relevant additional tests were done to evaluate the etiology. Anaemia was classified as normocytic if Mean Corpuscular Volume (MCV) was 83-101 fl (Osei-Bimpong et al., 2012). Any value above this was considered as macrocytic and any value below this as microcytic. Automated cell counter (Coulter LH500, Beckman Coulter) was used to measure haemoglobin and red cell indices on admission.

\section{Definition of Anaemia and nutritional deficiencies}

Absolute iron deficiency was defined as a serum ferritin $<30 \mathrm{ng} / \mathrm{mL}$. Functional iron deficiency was subcategorized as mild or moderate based on transferrin saturation $<16 \%$ and serum ferritin $>100 \mathrm{ng} / \mathrm{mL}$ or serum ferritin $30-100 \mathrm{ng} / \mathrm{mL}$, respectively (Ludwig et al., 2013; Aapro et al., 2012). Moreover, Anaemia was classified as microcytic $(<77 \mathrm{fl})$ and normocytic (77-96 fl). 
Factor associated to Anaemia are Genetic haemoglobin disorder, Nutrition and infectious disease factor (Fig.1).

\section{Estimation of relative prevalence of a depression in $\mathrm{Hb}$ concentration iron deficiency and inflammatory disease}

We estimated the relative prevalence of depressed $\mathrm{Hb}$ values due to iron deficiency or inflammatory disease by determining the shift in the median $\mathrm{Hb}$ concentration. Using the $50^{\text {th }}$ percentile to calculate relative prevalence has the advantage of including individuals in the lower half of the $\mathrm{Hb}$ (or hematocrit) distribution, where overlap between normal values and those influenced by iron deficiency is greatest (Garby et al., 1969). We performed these calculations by using the criteria described above. We use the term, relative prevalence to indicate that the values are merely estimates and that they are most useful in comparing prevalence according to age and sex. An example of the calculation of relative prevalence is as follows: in women between 25 and $34 \mathrm{yr}$ of age, the $50^{\text {th }}$ percentile for $\mathrm{Hb}$ concentration shifted from 13.29 to $13.41 \mathrm{~g} / \mathrm{dl}$ after excluding individuals on the basis of the above mentioned laboratory criteria. The new value of $13.41 \mathrm{~g} / \mathrm{dl}$ now corresponded to the 54.6th percentile of the original unscreened group, representing a shift of 4.6 percentiles or a relative prevalence of $4.6 \%$. We intentionally focused on iron deficiency in terms of its effects on $\mathrm{Hb}$ concentration since there is little convincing evidence that depletion of storage iron has adverse health consequences if the $\mathrm{Hb}$ concentration has not been affected (Dallman, 1982). Furthermore, the borderline between depletion of storage iron and the normally marginal state of iron stores in infants, children and young women may be arbitrary or difficult to define.

\section{Statistical analyses}

Reference ranges were derived only from groups in which the sample size exceeded 30 , based on an extrapolation from a recent report in which the minimum numbers for which reliable estimates of the $5^{\text {th }}$ and $95^{\text {th }}$ percentiles could be obtained was listed as 100 and the corresponding number for the $10^{\text {th }}$ and $90^{\text {th }}$ per centiles was 50 (Hong et al., 2012). Mean values for serum ferritin were calculated after logarithmic transformation because the values approach a log-normal distribution. The significance of differences between means was estimated by "Student's" $t$ test. The estimation of $95 \%$ confidence limits for relative prevalence of a depression in $\mathrm{Hb}$ concentration was based on the fact that mean and median values for $\mathrm{Hb}$ were virtually identical. We therefore assumed that the $95 \%$ range around the median $\mathrm{Hb}$ values in the screened population was equivalent in magnitude to the $\pm 2 \mathrm{SE}$ range around the mean. The $95 \%$ range in relative prevalence was then derived from the $\mathrm{Hb}$ percentiles of the original, unscreened group that corresponded to the assumed $95 \%$ confidence limits around the median $\mathrm{Hb}$ in the screened population.

\section{Results}

The developmental increase in values during childhood and the further rise in concentrations during adolescence in the male are in general accord with previously published values (Bothwell et al., 1979; Dallman et al., 1980). With increasing age in the adult, there was a slight rise in concentration of $\mathrm{Hb}$ in women and a substantial decline in men. The $95 \%$ range broadened in the elderly of both sexes but particularly in men. For the purposes of this report, the values listed for all races will be considered as reference values. The values for all races and for whites were very similar; Blacks accounted for only $12 \%$ of the total weighted population. However, in accordance with previous studies (Meyers et al., 1979), there was a lower median Hb concentration in Blacks than in whites that varied from $0.4 \mathrm{~g} / \mathrm{dl}$ in children between 3 and $5 \mathrm{yr}$ of age to $1.1 \mathrm{~g} / \mathrm{dl}$ in men between 65 and $74 \mathrm{yr}$ of age. The possible reasons for the difference in concentration of $\mathrm{Hb}$ and the extent to which it is due to genetic, socioeconomic, or dietary factors are important 
and complex issues but ones that requires more detailed analysis than is possible in this report. The basis for the discrepancy is unclear, but it does not appear to be attributable to a difference in prevalence of iron deficiency.

\section{Prevalence of Anaemia: percentage of values below the $95 \%$ reference range}

The percentage of individuals with $\mathrm{Hb}$ values below the reference range is shown according to age and sex on Table 1. The pattern of laboratory abnormalities of anemic subjects in those groups with a high relative prevalence of Anemia suggested differences in the predominant etiology of the Anaemia. Mean values for several laboratory tests in infants between 1 and 2 yr old, in women 25 to 44 and men 65 to $75 \mathrm{yr}$ of age are shown in Table 2. For each of these groups, laboratory values are shown for those whose concentration of $\mathrm{Hb}$ was in the anemic range compared to those with a $\mathrm{Hb}$ concentration above the lower limit of the reference range for age and sex (Table 2). In infants, young women, and elderly men, those who were anemic had lower Fe and Fe/TIBC, and higher EP values than the remaining group; the $\mathrm{MCV}$ was significantly depressed in the infants and young women but not in the elderly men. From these results alone, it was difficult to distinguish between iron deficiency and inflammatory disease as a major basis for Anaemia in each group (Bothwell et al., 1979; Dallman et al., 1980). However, the results of the TIBC and serum ferritin gave some indication of the relative contribution of the two conditions. TIBC is often depressed in individuals with inflammatory disease, infection, or protein deficiency, whereas it is elevated in many individuals with iron deficiency (Bothwell et al., 1979; Dallman et al., 1980). Serum ferritin is depressed in iron deficiency but typically elevated in inflammatory disease (Bothwell et al., 1979; Dallman et al., 1980). The mean TIBC was significantly elevated $(p<0.01)$ in anemic infants and young women but not in the anemic elderly men. The serum ferritin was depressed in the anemic young women $(\mathrm{p}<0.01)$ but not in the elderly men with Anaemia (no serum ferritin analyses were done in children under 3 yr old). These results indicate that iron deficiency was predominant as a cause of Anaemia in the infants and young women but that Anaemia seemed more commonly related to inflammatory disease and perhaps other conditions in elderly men.

Table: 1 Prevalence of Anaemia: percentage of values below the 95\% reference range

\begin{tabular}{|c|c|c|c|c|c|c|c|c|c|c|}
\hline $\operatorname{Age}(\mathrm{Yr})$ & $1-2$ & $3-5$ & $6-8$ & $9-11$ & $12-14$ & $15-17$ & $18-24$ & $25-44$ & $45-64$ & $65-75$ \\
\hline Male and Female & 5.7 & 3.5 & 2.3 & 2.8 & & & & & & \\
\hline Males & & & & & 2.9 & 2.9 & 2.9 & 2.9 & 3.8 & 4.4 \\
\hline Female & & & & & 3. & 5.9 & 5.9 & 5.8 & 3.9 & 3.9 \\
\hline
\end{tabular}

Table 2. Laboratory characteristics of anemic and non-anemic subjects $(n=354)$ (value below the 95\%)

\begin{tabular}{|l|c|c|c|c|c|c|c|c|c|}
\hline & Group: age (Yr) & $\mathrm{N}$ & $\begin{array}{c}\mathrm{Fe} * \\
\mu \mathrm{g} / \mathrm{gl}\end{array}$ & $\begin{array}{c}\text { TIBC } \\
\mu \mathrm{g} / \mathrm{gl}\end{array}$ & $\begin{array}{c}\text { Fe/TIBC } \\
\%\end{array}$ & $\begin{array}{c}\mathrm{MCV} \\
\mathrm{fl}\end{array}$ & $\begin{array}{c}\text { EP* } \\
\mu \mathrm{g} / \mathrm{gl} \text { red } \\
\text { blood cells }\end{array}$ & $\begin{array}{c}\text { Ferritin } \\
\mathrm{n} \\
\mu \mathrm{g} / \mathrm{gl}\end{array}$ \\
\hline Infants: & $1-2$ Anemic & 3 & 57.8 & 445 & 13.0 & 74.9 & 126.1 & \\
& Non anemic & 46 & 81.3 & 408 & 20.2 & 78.6 & 67.3 & \\
\hline \multirow{2}{*}{ Women } & $25-44$ Anemic & 40 & 78.8 & 392 & 20.4 & 87.5 & 71.6 & 66 & 14.9 \\
\cline { 2 - 10 } & Non anemic & 180 & 99.8 & 375 & 27.1 & 90.2 & 54.4 & 471 & 29.0 \\
\hline \multirow{2}{*}{ Men } & $65-75$ Anemic & 25 & 89.9 & 355 & 25.4 & 91.1 & 79.4 & 50 & 90.9 \\
\cline { 2 - 10 } & Non anemic & 50 & 102.2 & 348 & 29.5 & 91.0 & 51.2 & 296 & 93.8 \\
\hline
\end{tabular}

To convert to international system of units (SI), multiply Fe and TIBC values by 0.179 to obtain ${ }^{\mathrm{t} A n e m i c ~ g r o u p ~ d i f f e r s ~ f r o m ~ n o n-a n e m i c, ~} \mathrm{p}<0.01$; mol/I and multiply EP values by 10 to obtain $\mu \mathrm{g} / \mathrm{l}$ red blood cells. 


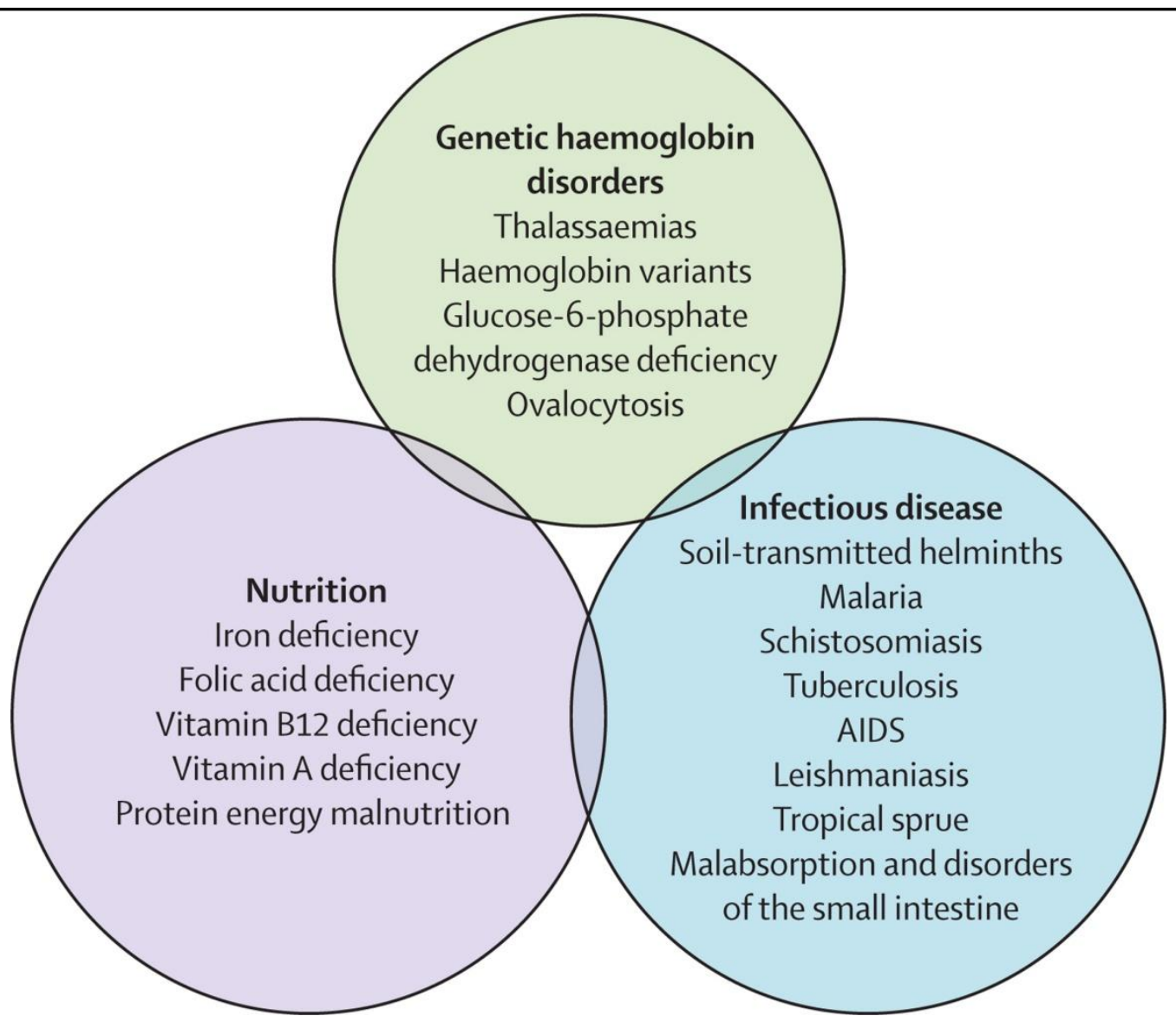

Fig. 1 Factor effect of Anaemia

\section{Discussion}

The results are helpful for deriving normative data for $\mathrm{Hb}$ and in delineating the degree to which iron deficiency and inflammatory disease influenced the concentration of $\mathrm{Hb}$ among various age/sex groups. Such data are helpful in developing rational routines for the laboratory detection of these conditions. The information also provides a base-line on which to study future trends in prevalence of Anaemia, iron deficiency, and inflammatory disease. In addition, the NHANES II data are useful as a background for public health policy decisions that pertain to the fortification of foods with iron. Anaemia is very common in elderly hospitalized patients, with a prevalence ranging from $2.9 \%$ to $66.3 \%$ (Joosten et al., 1992; Zamboni et al., 2006; Beghe et al., 2004). Possible causes for not pursuing these investigations could be death, obvious other serious pathology, such as metastatic carcinoma or severe dementia, and ignorance of the correct work-up of Anaemia. The majority of our patients had a mild normocytic Anaemia, the most likely cause in these cases being Anaemia of chronic disease, which was confirmed with special investigations in patients. The data for adult males are of interest in showing a definite peak in $\mathrm{Hb}$ concentration in the early twenties with a gradual decline thereafter to median values that were 1.0 $\mathrm{g} / \mathrm{dl}$ lower in the oldest age group. One distinct possibility is a decrease in an androgen stimulation of erythropoiesis that began during puberty. Another hypothesis proposed by (Lipschitz et al., 1981) is that Anaemia in otherwise healthy, aged subjects may indicate an overall reduction in hematopoietic reserve. The application of $\mathrm{Hb}$ reference values to elderly men will strongly influence the percentage that are considered anemic. Application of the same criteria for Anaemia to adult men of all ages might result in classifying a very large percentage of elderly men as anemic. Until there is strong 
evidence to the contrary, it seems reasonable to apply age-specific reference standards to elderly men. In contrast, the lower limit of the reference range remains almost constant in women, making it practical to use the same criterion for Anaemia at all adult ages. The apparent predominance of iron-deficiency Anaemia among children, adolescents, and women during the child-bearing years is in accord with previous data (Bothwell et al., 1979; Dallman et al., 1980). Increased iron requirements for rapid growth predispose to iron deficiency in children. In women, menstrual blood loss and the iron losses associated with pregnancy are major factors. Both Anaemia and depression in the concentration of $\mathrm{Hb}$ related to iron deficiency and chronic disorders in NHANES II were less common than might have been anticipated from earlier surveys (Dhew 1972; JAMA 1968). However, the oversampling of poverty groups in those surveys makes it difficult to draw conclusions about trends in the United States. The populations most affected in NHANES II were children, young women, and elderly men. The pattern of laboratory abnormalities indicated that iron deficiency was the major cause of the Anaemia in infants and young women, but that inflammatory disorders played a greater role in the elderly. The prevalence of either Anaemia or a depression in $\mathrm{Hb}$ concentration was well below $10 \%$ in all groups. This finding is in general accord with the more limited data available from NHANES 1(NCHS, 1982). It is difficult to make direct comparisons of NHANES I and II results because a number of laboratory tests, procedures, and quality control routines underwent changes between the two surveys; however, this will be the subject of a separate report from the National Center for Health Statistics. The results of NHANES II show that children and young women will continue to be the primary targets of efforts to decrease the prevalence of iron deficiency. In contrast, it cannot be anticipated that such efforts will have much influence on Anaemia in the elderly, which may prove to be more closely related to the state of general health and to socioeconomic conditions.

\section{Conclusion}

Overall prevalence of Anaemia was high in the study population. The most common cause of Anaemia was nutritional deficiency followed by chronic kidney disease and blood loss due to antiplatelet agents. The presence of Anaemia is a risk factor for increased morbidity and in-hospital mortality in these patients. As Anaemia is a relatively frequent condition which remains often under-diagnosed and untreated, its prevention and earlier detection may lead to improved outcomes. Mothers are fostering the future citizens of our societies. The conditions for mother and child in the postpartum, nursing and lactation period should be as favorable as possible. Many young mothers have a troublesome life due to iron deficiency causing a plethora of symptoms including fatigue, physical disability, cognitive problems, and psychiatric disorders. The most reliable way to obtain this goal is to give oral ferrous iron supplements from early pregnancy in doses ranging from 30 to $50 \mathrm{mg}$ daily and perform obstetric prophylactic measures in pregnancies at risk for complications.

\section{Conflict of Interest}

None of the authors of this paper have a financial or personal relationship with other people or organization that could inappropriately influence or bias the content of the paper.

\section{Acknowledgment}

I appreciate the supporting staff of Deptt of Physiology, VIMS for conducting this study. I am thankful to faculty member and supporting staff of Biochemistry department, VIMS for patients' information. I am highly grateful to Chairman sir, VIMS, Gajrola for given research place for this work. 


\section{References}

1. Bothwell TH, Charlton RW, Cook JD, Finch CA. Iron metabolism in man. Oxford: Blackwell Scientific Publications, 1979.

2. Dallman PR, Siimes MA, Stekel A. Iron deficiency in infancy and childhood. Am J Clin Nutr 1980;33:86-1 18.

3. Chalco JP, Huicho L, Alamo C, Carreazo NY, Bada CA. Accuracy of clinical pallor in the diagnosis of anaemia in children: a meta-analysis. BMC Pediatr. 2005; 5:46.

4. Kalantri A, Karambelkar M, Joshi R, Kalantri S, Jajoo U. Accuracy and reliability of pallor for detecting anaemia: a hospital-based diagnostic accuracy study. PLoS One. 2010;5 (1):8545.

5. Dallman PR. Manifestations of iron deficiency. Semin Hematol 1982;19:19-30.

6. FAO, WHO. World declaration and plan of action for nutrition: Food and Agriculture Organization of the United Nations; 1992.

7. Ferinject. Summary of Product Characteristics www.medicines.org.uk Accessed February $6^{\text {th }} 011$.

8. Lyseng-Williamson KA, Keating GM. Ferric carboxymaltose: a review of its use in iron-deficiency Anaemia. Drugs. 2009: 69:739-756.

9. Garby L, Irnell L, Werner I. Iron deficiency in women of fertile age in a Swedish community. III. Estimation ofthe iron status ofa population. Acts MedScand 1969; 185:113-17.

10. Iron deficiency in the United States. Committee on iron deficiency. JAMA 1968; 203:407-12.

11. Joosten E, Pelemans W, Hiele M, Noyen J, Verhaeghe R, Boogaerts MA. Prevalence and causes of anaemia in a geriatric hospitalized population. Gerontology. 1992; 38:111-7.

12. Ludwig H, Müldür E, Endler G, Hübl W. Prevalence of iron deficiency across different tumors and its association with poor performance status, disease status and Anaemia. Ann Oncol. 2013; 24 (7) :18861892.

13. Aapro M, Osterborg A, Gascon P, et al. Prevalence and management of cancerrelated anaemia, iron defciency and the specifc role of i.v. iron. Ann Oncol. 2012;23(8):1954-1962.

14. Meyers LD, Habicht J-P, Johnson CL. Components of the difference in hemoglobin concentrations in blood between black and white women in the United States. Am J Epidemiol 1979;109:539-49.

15. Monofer. Summary of Product Characteristics www.medicines.org.uk Accessed February $6^{\text {th }} 2011$

16. Mozaffarian D, Benjamin EJ, Go AS, Arnett DK, Blaha MJ, Cushman M. Heart disease and stroke statistics-2015 update: a report from the American heart association. Circulation. 2015;131 (4):29.

17. National Center for Health Statistics. Singer JD, Granahan P, Goodrich NN, Meyers LD, Johnson CL. Diet and iron status, a study of relationships: United States, 1971-74. Vital and health statistics. Series II, no 229. DHHS publication no (PHS) 83- 1679. Public Health Service. Washington, DC: US Government Printing Office, December 1982:36-7.

18. Lipschitz DA, Mitchell CO. Thompson C. The Anaemia of senescence. Am J Hematol 1981;1 1:47-54.

19. Osei-Bimpong A, McLean R, Bhonda E, Lewis $\mathrm{S}$. The use of the white cell count and haemoglobin in combination as an effective screen to predict the normality of the full blood count. International Journal of Laboratory Haematology. 2012; 34 (1): 91-97.

20. Hong YJ, Jeong MH, Choi YH, Song JA, Kim DH, Lee KH. Relation between anaemia and vulnerable coronary plaque components in patients with acute 
coronary syndrome: virtual histologyintravascular ultrasound analysis. Journal of Korean Medical Science. 2012; 27(4):370-76.

21. Merono O, Cladellas M, Recasens L, Garcia-Garcia C, Ribas N, Bazan V. Inhospital acquired Anaemia in acute coronary syndrome. Predictors, in-hospital prognosis and one-year mortality. Revista Española de Cardiología (English Edition). 2012; 65(8):742-48

22. Pasricha SR, Flecknoe-Brown SC, Allen KJ, Gibson PR, McMahon LP, Olynyk JK. Diagnosis and management of iron deficiency Anaemia: a clinical update. Med J Aust. 2010;193 (9):525-32.

23. Laxmaiah A, Rao M, Kumar RH, Arlappa N, Venkaiah K, Brahmam G. Diet and nutritional status of tribal population in ITDA project areas of Khammam district, Andhra Pradesh. J Hum Ecol. 2007;21 (2): 79-86.

24. Mozos I. Mechanisms linking red blood cell disorders and cardiovascular diseases. BioMed Research International. 2015.

25. Moura B. Anaemia and prognosis in acute coronary syndromes. Revista Portuguesa de Cardiologia (English Edition). 2012; 31(2):133-34.

26. Pedersen AN, Fagt S, Groth MV, Christensen T, Biltoft-Jensen, Matthiessen J. Dietary habits in Denmark 2003-2008. Main results: National Food Agency of Denmark. 2010.

27. Krafft A, Breymann C. Iron sucrose with and without recombinant erythropoietin for the treatment of severe postpartum Anaemia: a prospective, randomized, open-label study. J Obstet Gynaecol Res.2011; 37:119-124

28. Ten-state nutrition survey 1968-70. IV. Biochemical DHEW publication no (HSM) 72-8132. Atlanta, GA: US Department of Health, Education, and
Welfare, Centers for Disease Control, 1972.

29. Teunissen M, Hijmans CT, Cnossen MH, Bronner MB, Grootenhuis MA, Peters M. Quality of life and behavioral functioning in Dutch pediatric patients with hereditary spherocytosis. Eur J Pediatr. 2014; 173(9):1217-1223.

30. Trygg K, Lund-Larsen K, Sandstad B, Hoffman HJ, Jacobsen G, Bakketeig LS Do pregnant smokers eat differently from pregnant non-smokers? Paediatr Perinat Epidemiol. 1995; 9:307-319. Nordic Council of Ministers. Nordic Nutrition Recommendations 2004. Copenhagen 2004

31. Wang W, Bourgeois T, Klima J, Berlan ED, Fischer AN, O'Brien SH.. Iron deficiency and fatigue in adolescent females with heavy menstrual bleeding. Haemophilia. 2013;19 (2):225-230.

32. Panepinto JA, Torres S, Bendo CB, McCavit TL, Dinu B, Sherman-Bien S, Bemrich-Stolz C, Varni JW. PedsQL Multidimensional Fatigue Scale in sickle cell disease: feasibility, reliability, and validity. Pediatr Blood Cancer. 2014;61 (1):171-177.

33. Gv S, Pk S, Herur A, Chinagudi S, Patil SS, Ankad RB, Badami SV. Correlation between haemoglobin level and electrocardiographic (ECG) findings in anaemia: a cross-sectional study. J Clin Diagn Res. 2014;8 (4):BC04-06.

34. WHO, UNICEF, UNU. Iron defciency anaemia: assessment, prevention and control, a guide for programme managers. Geneva: World Health Organization. 2001.

35. Wonke B. Bone disease in betathalassaemia major. $\mathrm{Br} \mathrm{J}$ Haematol. 1998;103 (4):897-901.

36. World Health Organization. Haemoglobin concentrations for the diagnosis of anaemia and assessment of severity. Geneva, Switzerland: World Health 
Organization; 2011. Available from:

http://www.who.

int/vmnis/indicators/haemoglobin.pdf.

Accessed May 5, 2014.

37. Zamboni V, Cesari M, Zuccalà G, Onder G, Woodman RC, Maraldi C, Ranzini M, Volpato S, Pahor M, Bernabei R.. Anaemia and cognitive performance in hospitalized older patients: results from the GIFA study. Int $\mathbf{J}$ Geriatr Psychiatry. 2006; 21:529-34.

38. Beghe C, Wilson A, Ershler WB. Prevalence and outcomes of Anaemia in geriatrics: a systematic review of the literature. Am J Med. 2004;116 (7):3S-10. 